Instytut Archeologii

Uniwersytet Rzeszowski

Dariusz Bobak, Marta Połtowicz-Bobak

\author{
REGIONY OSADNICZE NA TERENACH POLSKI W MŁODSZEJ \\ FAZIE GÓRNEGO I POCZĄTKACH SCHYŁKOWEGO PALEOLITU \\ NA TLE OSADNICTWA ŚRODKOWOEUROPEJSKIEGO
}

Zarys treści: Praca dotyczy porównania rozprzestrzenienia osadnictwa graweckiego i magdaleńskiego na ziemiach polskich. Część eksploatowanych terytoriów ściśle się zazębia, zaobserwowano też różnice. Przesuwanie się osadnictwa graweckiego na wschód związane było ze zmianami klimatycznymi w początkach II pleniglacjału ostatniego zlodowacenia (LGM). Osadnictwo magdaleńskie rozprzestrzeniło się bardzo szybko, zajmując tereny ziem polskich aż po wschodnie granice swojego zasięgu. Struktura osadnicza obu kultur jest odmienna.

Słowa kluczowe: osadnictwo, Polska, grawetien, epigrawetien, magdalenien.

\title{
WSTĘP
}

Młodsza część interpleniglacjału to okres dużego ujednolicenia kulturowego obejmującego całą Europę, związanego z powstaniem i rozwojem kompleksu graweckiego. Jego kolebka znajdowała się na terenach Europy Środkowej, rozprzestrzeniał się na obszary zachodnio- i wschodnioeuropejskie (Otte, Noiret 2004). W tym czasie powstawały i rozwijały się wielkie centra o stabilnym osadnictwie.

\section{OSADNICTWO GRAWECKIE}

Starsza faza grawetienu - pavlovien, reprezentowana jest przez serię stanowisk tworzących korytarz łączący Dolną Austrię, Morawy i południowo-zachodnią Polskę (Svoboda 2007). Najstarsza faza (31 000?-27 000 BP) charakteryzuje się występowaniem dość rozproszonych, niewielkich stanowisk. Stopniowo jednak w tym okresie formowały się wielkie centra osadnicze 
(Svoboda 2007); największe i najbardziej rozpoznane pochodzą z południowych Moraw - przede wszystkim z Předmostí, Pavlova i Dolnich Věstonic (Svoboda Ložek, Vlček 1996; Oliva 2007), a także z Dolnej Austrii - Willendorf (Svoboda i in. 1996). Na ziemiach polskich koncentracje osadnictwa pavlovskiego występują na Górnym i Dolnym Śląsku, jednak jest to osadnictwo innego typu (Płonka, Wiśniewski 2004; Wiśniewski, Połtowicz-Bobak 2013). Na północ od Sudetów - jak dotychczas - nie odkryto bogatych stanowisk, analogicznych do wielkich, podstawowych obozowisk morawskich czy austriackich. Prawdopodobnie były to obszary peryferyjne osadnictwa graweckiego, eksploatowane przede wszystkim jako krzemienionośne (pozyskiwanie surowców kamiennych) oraz łowieckie. Stanowiska z ziem polskich nie mają datowań bezwzględnych, jednak na podstawie danych typologicznych łączone są z pavlovienem (Ginter 1966; Chmielewski 1975a; Kozłowski, Kozłowski 1977; Płonka, Wiśniewski 2004; Wiśniewski, Połtowicz-Bobak 2013); wśród nich także tego typu obozowiska (Wójcice, Henryków). Ślady wczesnego osadnictwa graweckiego znane są także z jaskiń w Małopolsce - Obłazowej (Obłazowa Cave 2003) oraz, być może, nowo odkrytej Borsuka, o ile znaleziska te można faktycznie odnosić do pavlovienu (Wilczyński $i$ in. 2014). Jednak także w tym przypadku nie mamy do czynienia z długo zasiedlanymi, dużymi obozowiskami (ryc. 1).

Dla początków II pleniglacjału ostatniego zlodowacenia (Last Glacial Maximum - LGM) odnotowano przesuwanie osadnictwa graweckiego na wschód. Z tego okresu pochodzą duże kompleksy stanowisk w Małopolsce - przy ulicy Spadzistej w Krakowie (Sobczyk 1995; Wilczyński, Wojtal, Sobczyk 2012) i zachodniej Słowacji - w rejonie Moravan nad Wagiem (Complex of Upper Palaeolithic 1995; 1998; Hromada 1998). Ubogie stanowiska graweckie znane są też z Krakowa-Przegorzał i Witkowic (Sobczyk 1995) oraz z Jaksic na Wyżynie Miechowskiej (Wilczyński i in. 2014). Obecnie powszechnie uważa się, że w młodszej fazie rozwoju osadnictwa graweckiego bliskie relacje łączyły Małopolskę z zachodnią Słowacją, przede wszystkim z kompleksem osadniczym w Moravanach (Kozłowski J. K. 1992; 2001; Kaminská, Kozłowski 2002) (ryc. 2). Jednocześnie odnotowano ślady wskazujące na zanik osadnictwa graweckiego na terenie Niemiec oraz wielkich centrów pavlovskich na południowych Morawach (Pavlov, Dolní Věstonice). Dla wspomnianego okresu na Morawach i w Austrii rejestrowane są duże stanowiska graweckie (Předmostí, Petřkovice, Willendorf) (Oliva 2007), ale nie mają one już rozmiarów kompleksów osadniczych znanych z pavlovienu.

Na sytuację osadniczą w Europie Środkowej miały wpływ zmiany klimatyczne i środowiskowe związane z rozwojem II pleniglacjału ostatniego zlo- 


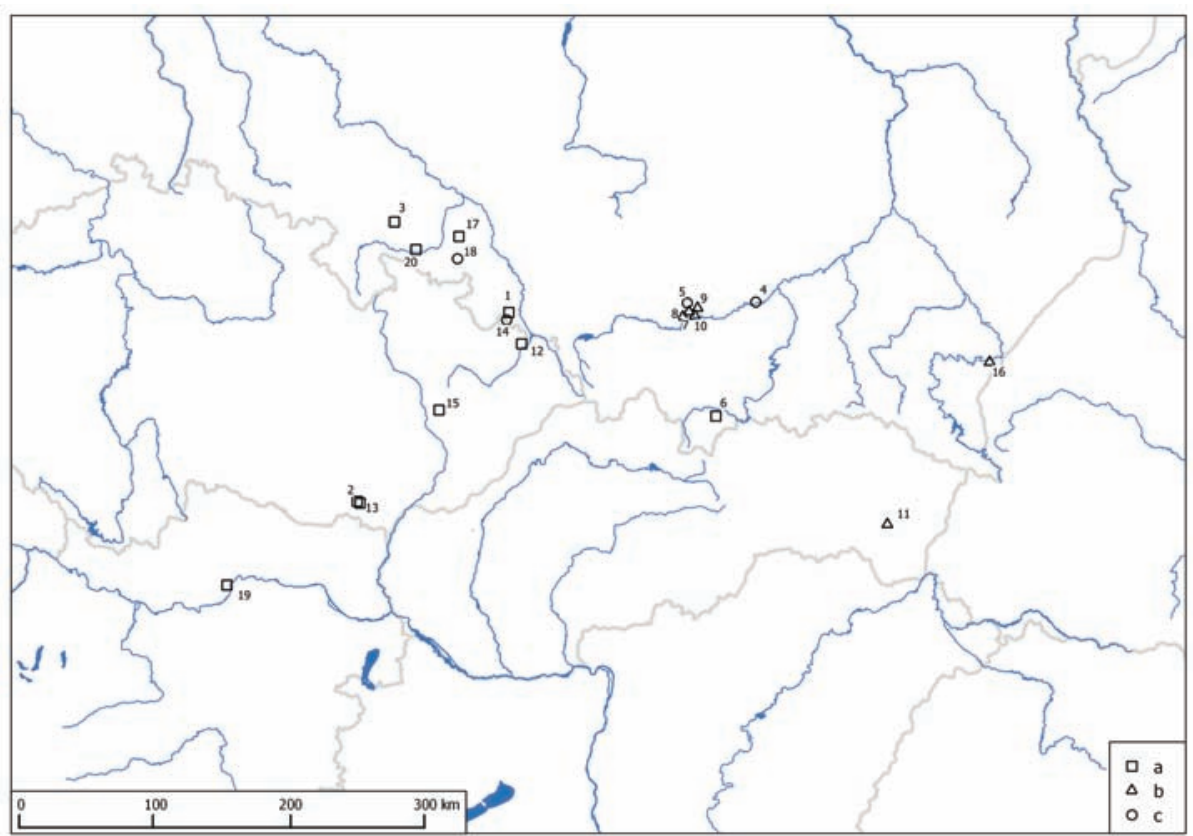

Ryc. 1. Najważniejsze stanowiska graweckie wymienione w tekście: a - stanowiska pavlovskie, b - stanowiska kostienkowsko-awdiejewskie, c - pozostałe stanowiska graweckie. 1 - Cyprzanów, 2 - Dolní Vestonice, 3 - Henryków, 4 - Jaksice, 5 - Jaskinia Borsucza, 6 - Jaskinia Obłazowa, 7 - Kraków, ul. Spadzista, 8 - Kraków-Przegorzały, 9 - Kraków-Witkowice, 10 - Kraków-Zwierzyniec, 11 - Moravany, 12 - Ostrava-Petřkovice, 13 - Pavlov, 14 - Pietraszyn, 15 - Předmostí, 16 - Przemyśl, 17 - Sowin, 18 - Śmicz, 19 - Willendorf, 20 - Wójcice (rys. D. Bobak)

Fig. 1. The most important gravettien sites mentioned in text: a - Pavlovien sites, b Kostienki-Avdieyevo sites, c - other Gravettien sites. 1 - Cyprzanów, 2 - Dolní Vestonice, 3 - Henryków, 4 - Jaksice, 5 - Jaskinia Borsucza, 6 - Jaskinia Obłazowa, 7 - Kraków, ul. Spadzista, 8 - Kraków-Przegorzały, 9 - Kraków-Witkowice, 10 - Kraków-Zwierzyniec, 11 - Moravany, 12 - Ostrava-Petřkovice, 13 - Pavlov, 14 - Pietraszyn, 15 - Předmostí, 16 - Przemyśl, 17 - Sowin, 18 - Śmicz, 19 - Willendorf, 20 - Wójcice (drawn by D. Bobak)

dowacenia. Osadnictwo nie tylko stopniowo zanikało, ale także zmieniała się jego struktura. Około 20 tysięcy lat BP rozległe obszary Europy, w tym także jej środkowej części, niemal pozbawione były osadnictwa (Housley i in. 1997; Street, Terberger 1999; Terberger, Street 2002; Gamble i in. 2004; Terberger 2013). Z opisywanych terenów znane są tylko pojedyncze punkty osadnicze łączone z epigrawetienem bądź też z jednostką taksonomiczną określaną jako grubgrabien, względnie kašovien (Terberger 2003; 2013; Svoboda, Novak 2004). 
W Polsce stanowiska datowane na okres 20-17 tysięcy lat BP koncentrują się w Małopolsce, skąd znane są nieliczne ślady osadnictwa łączone z działalnością łowiecką (np. Kraków-Nowa Huta, Kraków, ulica Spadzista C2, Jaskinia Deszczowa, Jaskinia Mamutowa i inne; Kozłowski, Kubiak, Welc 1970; Sobczyk 1995; Cyrek 1999; Kozłowski J. K. 1999; Cyrek i in. 2000; Terberger 2013) oraz pracownie (Piekary, Kraków, ulica Spadzista B; Wilczyński 2006; 2007). Również z ościennych terenów pochodzą nieliczne ślady osadnictwa $\mathrm{z}$ tego czasu (ryc. 2).

Osadnictwo LGM w środkowej części Europy jest bardzo ubogie i rozproszone. Nie da się wydzielić wyraźnych koncentracji punktów osadniczych, może poza dwoma rejonami: Małopolską i wschodnią Słowacją, skąd znane są takie stanowiska jak Kašov czy Cejkov (Bánesz i in. 1992; Kaminská, Tomášková 2004).

W Małopolsce kluczową rolę odgrywały, jak się wydaje, wychodnie surowców krzemiennych. Stanowiska łowieckie, zarówno w typie obozowisk, jak i klasycznego killing site (miejsca ubicia zwierzyny), wskazują także na inny sposób wykorzystania terytorium. Pytanie czy obie te funkcje miały równorzędne znaczenie, czy też łowiectwo odbywało się niejako przy okazji wędrówek w poszukiwaniu surowców, musi pozostać otwarte.

W strukturach osadnictwa graweckiego i epigraweckiego widoczne są bardzo wyraźne różnice. Przede wszystkim dla LGM odnotowano zanik wielkich obozowisk podstawowych, zasiedlanych przez długi czas, którym towarzyszyły krótkotrwałe obozowiska łowieckie, użytkowane przez niewielkie grupy ludzi. Zmienił się także charakter obozowisk, co przejawia się zarówno w ich znacznie mniejszych zasięgach przestrzennych, jak i na przykład w braku złożonych struktur nieruchomych. Dla epigrawetienu stwierdzono też zanik wyrobów sztuki (Kozłowski J. K. 1997). Te różnice wynikają z daleko idących zmian kulturowych i gospodarczych, uwarunkowanych przemianami środowiskowymi, które miały wpływ chociażby na dostępność zwierzyny łownej, a co za tym idzie, także strategii polowań, warunkującej $\mathrm{z}$ kolei system osadnictwa.

\section{OSADNICTWO MAGDALEŃSKIE}

Sytuacja zmieniła się dopiero w początkach schyłkowego plejstocenu. Rekolonizowane tereny dzisiejszej Polski, Moraw, Czech i Niemiec znalazły się wówczas w „zachodnioeuropejskiej strefie kulturowej”, reprezentowanej przez kompleks magdaleński. Kultura przyniesiona przez ludność magda- 


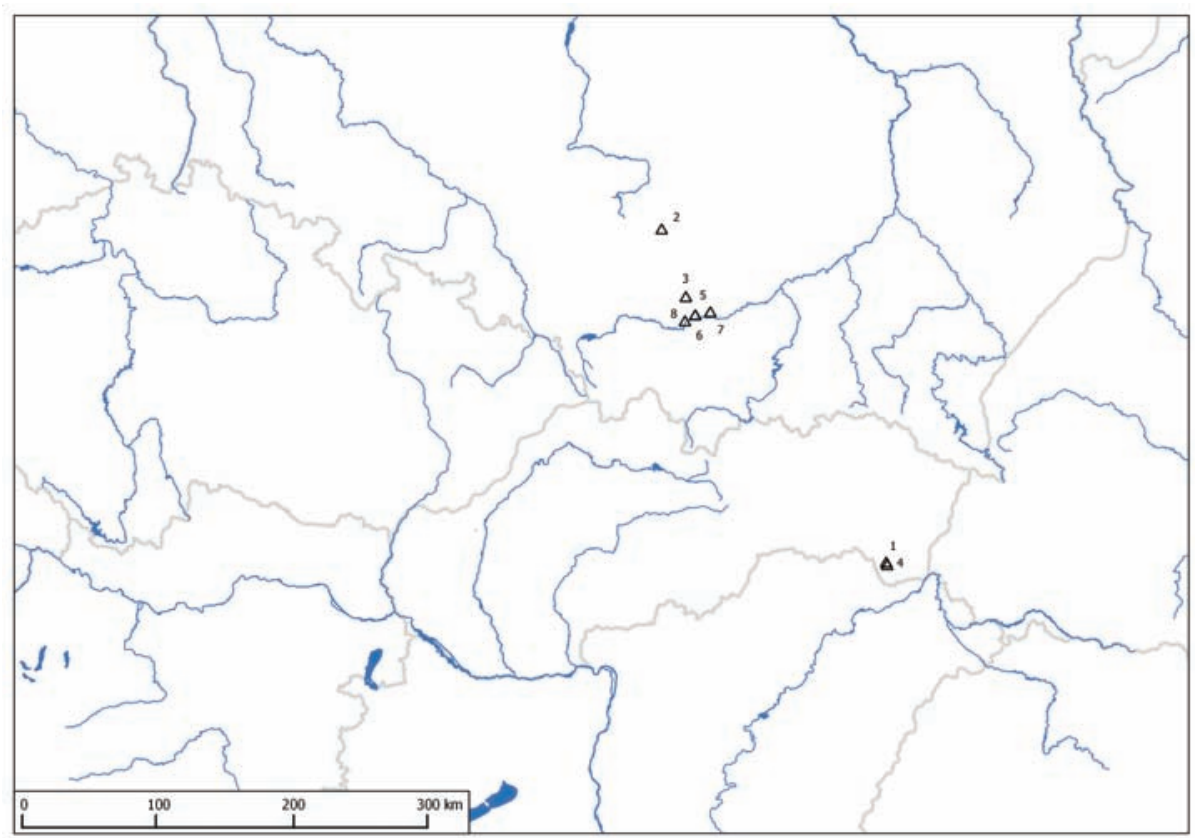

Ryc. 2. Najważniejsze stanowiska epigraweckie wymienione w tekście: 1 - Cejkov, 2 - Jaskinia Deszczowa, 3 - Jaskinia Mamutowa, 4 - Kašov, 5 - Kraków, ul. Spadzista B, 6 - Kraków, ul. Spadzista C2, 7 - Kraków Nowa Huta, 8 - Piekary (rys. D. Bobak)

Fig. 2. The most important Epigravettian sites mentioned in text. : 1 - Cejkov, 2 - Jaskinia Deszczowa, 3 - Jaskinia Mamutowa, 4 - Kašov, 5 - Kraków, ul. Spadzista B, 6 Kraków, ul. Spadzista C2, 7 - Kraków Nowa Huta, 8 - Piekary (drawn by D. Bobak)

leńską, rozprzestrzeniła się na obszarze Europy Środkowej, a jednocześnie pozostała nad wyraz spójna i zachowała przez cały okres trwania tradycje silnie nawiązujące do magdalenienu zachodnioeuropejskiego. W obrębie tego kręgu kulturowego nie znalazły się tereny Słowacji, pozostały one w strefie osadnictwa epigraweckiego, kontynuując epigrawecki model osadnictwa (Kaminská 2007). W Europie Środkowej można wyróżnić kilka koncentracji osadnictwa magdaleńskiego. Jego struktura opierała się zasadniczo na istnieniu obozowisk typu podstawowego, którym towarzyszyły krótkotrwałe obozowiska łowieckie, niekiedy także pracownie. Model ten znany jest z całego magdalenienu.

Osadnictwo magdaleńskie obejmowało pas wyżyn i pogórzy po obu stronach Karpat i Sudetów, sięgając po granicę wyżyn i Niżu Środkowoeuropejskiego. Tereny te charakteryzuje urozmaicona rzeźba, ale z preferencją do form łagodnych, pagórkowatych bądź falistych (Połtowicz-Bobak 2013). Widoczny jest także związek z rzekami - zarówno dużymi, takimi jak Soława, Ochrza, Berounka, Morawa, Odra, Wisła i San, jak też z mniejszymi, 
o lokalnym znaczeniu. Mogły one być zarówno ważnymi szlakami komunikacyjnymi, jak też barierami dla rozwoju osadnictwa. Być może taką barierą (lub jedną z barier) były Wisła i San, które według dzisiejszego stanu badań faktycznie uznawane są za wschodnią rubież osadnictwa magdaleńskiego; poza linią tych rzek znajdują się tylko pojedyncze stanowiska (Klementowice-Kolonia i Hłomcza). Zapewne jednak ostateczną wschodnią granicę stanowił Bug (Połtowicz-Bobak 2013).

Rozmieszczenie osadnictwa magdaleńskiego nie jest jednolite. Można wskazać kilka regionów z rysującymi się koncentracjami stanowisk, a także takie, z których znane są rozproszone bądź pojedyncze stanowiska. Regiony te, $z$ bardziej lub mniej intensywnymi śladami pobytu ludności magdaleńskiej, są rozdzielone terenami, z których nie są znane żadne pozostałości osadnictwa związanego $\mathrm{z}$ tą jednostką taksonomiczną. Widać to na całym obszarze występowania magdalenienu zarówno w Europie Środkowej, jak i Zachodniej. We wschodniej części Europy Środkowej najważniejsze skupiska odnotowano w Turyngii i Saksonii, w środkowych Niemczech (Weniger 1987; 1989), na Krasie Morawskim i Czeskim, w dolinie rzeki Ochrzy, na Śląsku, po obu stronach Bramy Morawskiej, w Małopolsce, w tym też na Jurze Krakowsko-Częstochowskiej oraz w południowo-wschodniej Polsce (ryc. 3). Mają one różną wielkość i strukturę; obok terenów o wyraźnych granicach i dużej bądź stosunkowo dużej liczbie stanowisk różnych typów (Turyngia, Kras Morawski, Kras Czeski), rysują się także takie, w których gęstość ta jest znacznie mniejsza, a granice silnie rozmyte (Połtowicz-Bobak 2013). Taka „rozmyta” struktura osadnictwa dominuje przede wszystkim na ziemiach polskich, co odróżnia je od większości pozostałych zasiedlonych przez ludność magdaleńską. Osadnictwo magdaleńskie występuje tu w kilku regionach tworzących centra, ale już ich typowa struktura złożona z jednego bądź kilku dużych stanowisk w typie obozowisk podstawowych, którym towarzyszą mniejsze stanowiska ,satelickie” nie jest jednoznaczna. Trudne do wyznaczenia są także granice ich zasięgu.

Najbardziej wyraźną koncentracją, o dających się określić granicach, jest niewielkie skupienie w południowej części Jury Krakowsko-Częstochowskiej. Widać tu wyraźne nawiązania do modelu znanego z innych części Europy, jednak odnotowano też znaczące różnice. Przede wszystkim nie zidentyfikowano bogatego stanowiska w typie długo zasiedlanego czy wielokrotnie odwiedzanego obozowiska podstawowego, z wyjątkiem Jaskini Maszyckiej, która jednak jest śladem znacznie wcześniejszego epizodu osadniczego i nie ma żadnego związku z późnym magdalenienem. Wszystkie stanowiska są ubogie, w typie halte de chasse lub pracowni (jaskinia w Zalasie). Duże sta- 


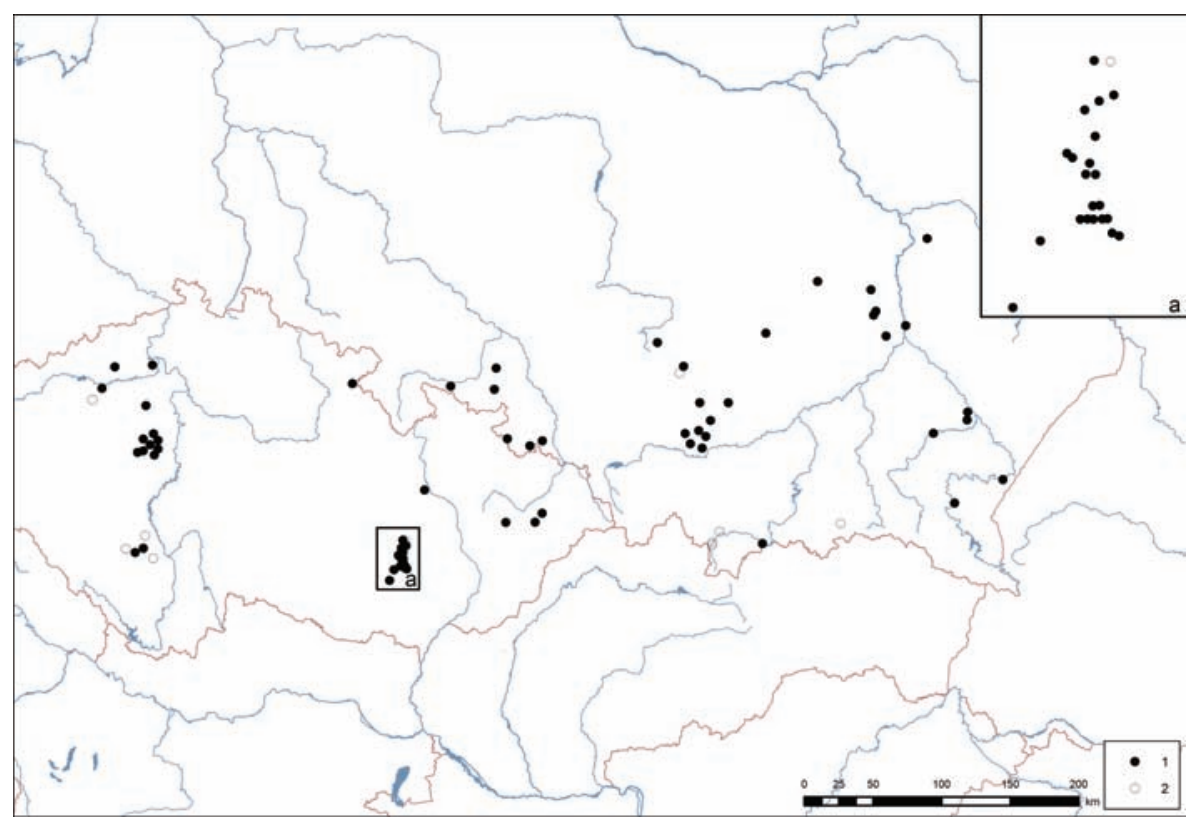

Ryc. 3. Stanowiska magdaleńskie w Polsce, na Morawach i w Czechach (wg Połtowicz-Bobak 2013, ryc. 34)

Fig. 3. Magdalenian sites in Poland, Moravia and Czech (after Połtowicz-Bobak 2013, ryc. 34)

nowiska $\mathrm{z}$ tego regionu to wyłącznie pracownie (Brzoskwinia, Wołowice). Taka struktura osadnictwa wyraźnie odróżnia Jurę Krakowską od krasowych terenów Czech (Kras Czeski) i Moraw (Kras Morawski), gdzie obserwuje się współwystępowanie dużych i ważnych obozowisk typu podstawowego z ubogimi stanowiskami łowieckimi. Zarówno Kras Morawski, jak i Czeski stanowiły bardzo ważne centra osadnicze w magdalenienie. W Krasie Morawskim koncentruje się ponad 80\% wszystkich stanowisk morawskich, zaś w Krasie Czeskim 50\%, podczas gdy z Jury Krakowsko-Częstochowskiej pochodzi tylko około 30\% stanowisk. Co więcej, osadnictwo magdaleńskie nie jest, jak dotąd, znane z Jury Ojcowskiej, gdzie odkryto najważniejsze stanowiska z wcześniejszych okresów starszej epoki kamienia (Połtowicz-Bobak 2013 - tam dalsza literatura). Obserwacja ta jest istotna, wskazuje bowiem, że o ile obszary krasowe pełniły ważną funkcję w osadnictwie magdaleńskim (Svoboda i in. 1996), to jednak nie zawsze stawały się dominującymi centrami osadniczymi. Widać to zarówno w przypadku Jury Krakowsko-Częstochowskiej, jak i Štramberskiego Krasu na Śląsku w Republice Czeskiej (Valoch 1965). 
Poza terenem jurajskim na ziemiach polskich zaobserwowano koncentracje mniejsze i na ogół bardziej rozproszone: stanowiska magdaleńskie odkryto na Śląsku, w południowo-wschodniej Polsce i na Wyżynie Sandomierskiej, pojedyncze - w środkowej i północnej części Wyżyny Krakowsko-Częstochowskiej, rejonie Gór Świętokrzyskich, Płaskowyżu Nałęczowskiego, a także Karpat.

O ile struktura osadnictwa na Morawach, w Czechach czy Niemczech jest dość dobrze czytelna (współwystępujące obozowiska duże i małe), o tyle niektóre rejony Polski odbiegają od tego modelu. Dotyczy to, poza Jurą Krakowsko-Częstochowską, południowo-wschodniej Polski i Karpat, skąd nie są znane duże obozowiska podstawowe, a także Kotliny Sandomierskiej, skąd z kolei pochodzą dwa duże obozowiska (Wilczyce, Ćmielów-Mały Gawroniec). Duże obozowisko znajduje się też dalej na wschód, na Płaskowyżu Nałęczowskim (Klementowice-Kolonia). Charakterystyczne jest przy tym, że ta nietypowa struktura dotyczy zasadniczo terenów położonych na wschód od Śląska. Być może cały ten rozległy obszar na wschód od Wisły należy traktować jako jeden region osadniczy eksploatowany przez te same społeczności. Byłby on znacznie większy niż w innych miejscach wschodniej części Europy Środkowej, ale jednocześnie o wiele słabiej okupowany(?). Ten bardzo rozproszony charakter osadnictwa, odróżniający zasadniczo tereny wschodniej części Polski od typowych koncentracji osadnictwa magdaleńskiego, być może wynika z faktu, że są to już dalekie rubieże magdalenienu.

\section{DYSKUSJA}

Na obszarach zasiedlanych przez ludność grawecką i magdaleńską można zaobserwować kilka różnic dotyczących lokalizacji stanowisk. Stanowiska magdaleńskie są bezsprzecznie bardziej liczne, biorąc pod uwagę nie tylko ich liczbę bezwzględną, ale także o wiele krótszy czas, z którego pochodzą. Może to wynikać częściowo ze stanu ich zachowania, niemniej jednak, jak się wydaje, mamy tu do czynienia $\mathrm{z}$ faktycznym zwiększeniem liczby śladów osadnictwa. Na szczególną uwagę zasługują natomiast regiony, w których występują stanowiska tych dwóch dużych kompleksów kulturowych. Osadnictwo graweckie w Polsce odnotowano w dwóch rejonach: na Górnym i Dolnym Śląsku oraz w zachodniej części Małopolski, tj. w okolicach Krakowa i w Karpatach. Najdalej wysunięte na wschód jest odizolowane stanowisko w Przemyślu przy ul. Słowackiego, odkryte na terenie dawnej cegielni Teicha (Kozłowski J. K. 1963; Połtowicz 2004). Można więc uznać, że osad- 
nictwo graweckie obejmuje całą południową Polskę, podobnie jak osadnictwo magdaleńskie. Jednak bardziej szczegółowe obserwacje pozwalają dostrzec mikrorejony, w których osadnictwo obu jednostek pokrywa się oraz takie, w których występuje tylko jedna z nich. Do tych ostatnich należy zaliczyć Dolny Śląsk, skąd pochodzą ślady osadnictwa graweckiego w postaci obozowiska w Henrykowie (Płonka, Wiśniewski 2004); jest to jednocześnie teren, z którego, jak dotąd, nie są znane stanowiska magdaleńskie. Znajdują się one natomiast w Broniszowicach (Krawczyk, Płonka, Wiśniewski 2004) i Sowinie, odległych o mniej niż $50 \mathrm{~km}$ od Henrykowa. Można zatem uznać, że zachodni zasięg grawetienu i magdalenienu był zbliżony.

Osadnictwo obu jednostek taksonomicznych jest z kolei dobrze poświadczone na Górnym Śląsku, po północnej stronie Bramy Morawskiej (Wiśniewski, Połtowicz-Bobak 2013), co potwierdza istotną rolę tego obszaru, a przede wszystkim obniżenia pomiędzy pasmem Karpat i Sudetów. Należy uznać, że dla społeczności reprezentujących wymienione jednostki kulturowe tereny położone na północ od Bramy Morawskiej miały podobne znaczenie. Stanowiły zaplecze surowcowe, co poświadczają pracownie - graweckie odkryte w Cyprzanowie, Śmiczu (Wiśniewski i in. 2010; Wiśniewski, Połtowicz-Bobak 2013 - tam dalsza literatura) oraz magdaleńska (współwystępująca z obozowiskiem) w Sowinie (Wiśniewski i in. 2012). Były także eksploatowane łowiecko, o czym świadczą stanowiska graweckie i magdaleńskie, wśród których można wyróżnić zarówno dłużej zasiedlane obozowiska podomowe, jak i krótkotrwałe obozowiska łowieckie (Wiśniewski, Połtowicz-Bobak 2013 - tam dalsza literatura).

Zasadniczo na Śląsku osadnictwo graweckie i magdaleńskie stwierdzono na tych samych obszarach z tym, że według dzisiejszego stanu badań, grawetien sięga zapewne nieco dalej na zachód. Podobnie osadnictwo graweckie i magdaleńskie pokrywa się terytorialnie po południowej stronie Bramy Morawskiej, na Śląsku Czeskim (Svoboda i in. 2002; Oliva 2007). Być może na tych terenach osadnictwo graweckie było bardziej intensywne, jednak w świetle dostępnych źródeł tezę tę należy traktować ostrożnie.

Osadnictwo graweckie i magdaleńskie współwystępuje również w Małopolsce, choć dostrzegalne są też znaczące różnice w jego rozmieszczeniu. Dotyczy to przede wszystkim Krakowa i jego najbliższej okolicy. Z samego miasta znane są liczne stanowiska paleolityczne, w tym graweckie, przede wszystkim wielki kompleks Kraków, ulica Spadzista. Odkryte pozostałości wskazują, że miejsca te były intensywnie eksploatowany od 24 do 18 tysiąclecia BP (w latach niekalibrowanych). Nieliczne ślady osadnictwa graweckiego odkryto też na stanowisku Kraków-Zwierzyniec (Sobczyk 1995). Natomiast 
z Krakowa do dziś nie są znane żadne ślady osadnictwa magdaleńskiego. Osadnictwo na Jurze poświadczone jest słabiej w przypadku grawetienu niż magdalenienu, choć w wyniku nowych badań odkryto pozostałości pobytu ludności graweckiej (Wilczyński i in. 2014). Podobną sytuację - brak stanowisk graweckich - odnotowano na Morawach i w Czechach, co może wskazywać, że ludność grawecka nie była zainteresowania zasiedlaniem jaskiń terenów jurajskich. Z Jury pochodzą natomiast stanowiska epigraweckie (jaskinie - Mamutowa, Zawalona, Deszczowa). Do nowo odkrytych należy stanowisko graweckie w Jaksicach na Wyżynie Miechowskiej (Wilczyński $\mathrm{i}$ in. 2014); jest to teren lessowy, położony około $30 \mathrm{~km}$ na północny wschód od Krakowa. Nie stwierdzono tam natomiast żadnego śladu osadnictwa magdaleńskiego.

Zasiedlane zarówno przez ludność grawecką, jak i magdaleńską były tereny Karpat. Pojedyncze stanowiska magdaleńskie pochodzą przede wszystkim ze Sromowców Wyżnych-Kątów w Pieninach (Valde-Nowak 1991), ważne stanowisko graweckie odkryto w Jaskini Obłazowej (Obłazowa Cave 2003). Ślady osadnictwa ze Sromowców Wyżnych-Kątów interpretowane są jako pracownia, w której obrabiano radiolaryt; wykorzystywanie tego surowca poświadczone jest na obszarze Małopolski.

Pozostałości osadnictwa graweckiego i magdaleńskiego współwystępują też na terenach południowo-wschodniej Polski. Co prawda, znajduje się tu tylko jedno pewne stanowisko graweckie z Przemyśla, przy ul. Słowackiego (Połtowicz 2004), ale jest ono dobrze udokumentowane. Przynależność do grawetienu półtylczaka znalezionego na powierzchni w miejscowości Wesoła na Pogórzu Dynowskim (Dagnan-Ginter, Parczewski 1976) oraz drapacza w Orzechowcach (Połtowicz 2004) należy uznać za niepewną. Na wspomnianych wyżej terenach odkryto nieco więcej stanowisk magdaleńskich. Z Przemyśla pochodzi kościany harpun (Kozłowski S. K. 1977), poza tym z południowo-wschodniej Polski znanych jest jeszcze kilka stanowisk w typie krótkotrwałych obozowisk. Stanowiska magdaleńskie są wyraźnie powiązane z doliną Sanu i - w jednym przypadku - jego dopływu - Wisłoka (Łąka), co może wskazywać zasadniczy kierunek wędrówek - z południa na północ. $\mathrm{Z}$ kolei położenie graweckiego stanowiska w Przemyślu interpretuje się jako powiązane $\mathrm{z}$ drogą prowadzącą $\mathrm{z}$ zachodu na wschód $\mathrm{i}$ kojarzoną z przesuwaniem osadnictwa kostienkowsko-awdiejewskiego z zachodniej Małopolski na Ukrainę i Nizinę Rosyjską (Kozłowski, Kozłowski 1996). Na kierunek północ-południe jako znaczącą oś rozprzestrzeniania się osadnictwa magdaleńskiego wskazują też stanowiska z Wyżyny Sandomierskiej oraz Płaskowyżu Nałęczowskiego. 
Tereny położone na wschód od Wisły charakteryzują się nie tylko bardzo dużym rozproszeniem stanowisk magdaleńskich, ale także ich dość specyficzną strukturą. Z południowo-wschodniej Polski i Karpat pochodzą tylko ubogie, krótkotrwale zasiedlane obozowiska i pracownie, natomiast bogate stanowiska w typie obozowisk podstawowych odkryto na Wyżynie Sandomierskiej i Płaskowyżu Nałęczowskim. Wydaje się, że tereny te mogły być ze sobą powiązane, tworząc terytorium eksploatowane przez te same społeczności. Być może z nimi należy łączyć obszary jurajskie i stanowiska położone przy granicy wyżyn i Niżu Polskiego - w Mostach i Grzybowej Górze (Połtowicz-Bobak 2013).

Drugim, wyróżniającym się terytorium, eksploatowanym zapewne przez łowców magdaleńskich był Śląsk, zarówno polski, jak i czeski; prawdopodobnie wykorzystywana było przez te same grupy ludności. Granica między tymi strefami biegnie na zachód od Jury Krakowsko-Częstochowskiej oraz przez Wyżynę Śląską (Połtowicz-Bobak 2013). Warto przy tym wspomnieć, że nie ma różnic chronologicznych w zasiedlaniu wspomnianych obszarów. Mamy tu więc dwa głównie regiony osadnicze, analogicznie jak w przypadku grawetienu. Tereny Śląska są w obu przypadkach powiązane z Morawami. W Małopolsce można wyznaczyć kierunki relacji grawetienu z obszarami położonymi zarówno na południu (Słowacja), jak i na wschodzie (Ukraina), co jest związane z przesuwaniem się osadnictwa w miarę postępowania zmian klimatycznych II pleniglacjału. W przypadku magdalenienu należy poszukiwać związków z terenami Śląska i Moraw.

Zasadniczo więc obszary zajęte przez grawetien i magdalenien są analogiczne, a różnice widoczne są dopiero w skali mikroregionalnej. Część z ich pokrywa się ze sobą; jest to cecha, która odróżnia ziemie polskie od Moraw i Czech, na których rozdzielność osadnictwa graweckiego i magdaleńskiego jest znacznie wyraźniejsza.

Wyraźne różnice w osadnictwie ludności graweckiej i magdaleńskiej na ziemiach polskich widoczne są natomiast, gdy weźmie się pod uwagę kwestie chronologiczne. Osadnictwo graweckie na Śląsku związane jest z pavlovienem i umiejscawiane w okresie od 29 do 26 tysiąclecia BP. W Małopolsce jest ono młodsze (z wyjątkiem pavlovskiego poziomu z Jaskini Obłazowej i Jaskini Borsuczej) i łączone z kulturą kostienkowsko-awdiejewską: kompleks z Krakowa, ulicy Spadzistej, znaleziska z Krakowa-Zwierzyńca (Chmielewski 1975b) oraz z Przemyśla, cegielni Teicha. Najstarsze daty ${ }^{14} \mathrm{C}$ ze stanowiska na ulicy Spadzistej wskazują na 25 tysiąclecie, a więc na wczesny LGM i związane z nim migracje. Te dwa wyżej wspomniane regiony były więc 
zasiedlane zasadniczo w innym czasie, a przesuwanie osadnictwa na wschód wynikało ze zmian klimatycznych i środowiskowych.

Z inną sytuacją mamy do czynienia w okresie trwania kultury magdaleńskiej. Pomijając epizod z Jaskini Maszyckiej można stwierdzić, że osadnictwo tej jednostki taksonomicznej rozprzestrzeniło się bardzo szybko, zajmując tereny ziem polskich aż po wschodnie granice swojego zasięgu. Daty z Wilczyc, Klementowic-Kolonii (Klementowice 2013) oraz być może z Homczy wskazują, że obszary położone przy wschodnich i północno-wschodnich rubieżach osadnictwa były zasiedlone w okresie poprzedzającym ciepłą oscylację GI-1e (Bølling), a więc nie później niż pozostałe tereny ziem polskich, jak i inne ze wschodniej części Europy Środkowej (Połtowicz-Bobak 2013 - tam dalsza literatura). Czas osadnictwa w strefie karpackiej (Pieniny) nie może zostać jednoznacznie ustalony ze względu na brak datowań, stąd też trudno obecnie stwierdzić, czy także i tereny podgórskie były zasiedlane w okresie zimnego stadiału GS-2a. Niemniej jednak już na podstawie dostępnych danych widać, że przesuwanie się osadnictwa magdaleńskiego na wschód nie było ściśle uzależnione od zmian klimatycznych lecz, jak należy przypuszczać, wynikało z procesów kulturowych i demograficznych prowadzących do stopniowego rozszerzania zasiedlanego terytorium.

\section{ZAKOŃCZENIE}

Obserwacje dotyczące rozprzestrzenienia osadnictwa graweckiego i magdaleńskiego pokazują, że ludność obu kompleksów kulturowych zasadniczo zajmowała podobne strefy geograficzne, aczkolwiek widoczne są też zasadnicze różnice. Zarówno w grawetienie, jak i magdalenienie tereny ziem polskich stanowiły obszary peryferyjne, co jest zrozumiałe, biorąc pod uwagę fakt, że były położone stosunkowo daleko na północ. Widoczne jest tu znaczenie Bramy Morawskiej, poświadczone także dla wcześniejszych okresów paleolitu (Bobak, Połtowicz-Bobak 2010), a także terenów podkrakowskich, choć w tym przypadku obserwuje się znaczące różnice w położeniu stanowisk na poziomie mikroregionów. Stanowiska graweckie i magdaleńskie występują też w Karpatach. W tym kontekście warto zwrócić uwagę, że o ile graweckie położone są po obu stronach łańcucha górskiego - w Małopolsce i na Słowacji, to na tym ostatnim terytorium, jak dotąd, nie znaleziono niebudzących wątpliwości stanowisk magdaleńskich. Połączenie tych dwóch faktów zdaje się wskazywać, że zasięg magdalenienu nie przekroczył Karpat (Pienin, Bieszczadów) nie z powodu tego, że góry te były barierą, lecz ra- 
czej stanowiły granicę kulturową, dzielącą świat magdaleński i epigrawecki (Połtowicz-Bobak 2013). Tereny południowo-wschodniej Polski są, jak dotąd, zbyt słabo przebadane, aby na podstawie dostępnych danych można było formułować bardziej szczegółowe wnioski dotyczące zagadnień osadniczych, a przede wszystkim rozstrzygać, jakie były przyczyny tego zróżnicowania. Wydaje się, że obok uwarunkowań klimatycznych i środowiskowych, których wpływ jest widoczny zwłaszcza w przypadku osadnictwa graweckiego, ważną rolę odgrywały też czynniki kulturowe.

Przedstawione tu konkluzje nie pretendują oczywiście do ostatecznych czy wyczerpujących. Należy je raczej traktować jako propozycję do dyskusji i pole do dalszych badań, warunkowanych także nowymi odkryciami.

\section{LITERATURA}

Bánesz L., Hromada J., Desbrosse R., Margerand I., Kozłowski J. K., Sobczyk K., Pawlikowski M.

1992 Le site de plein air du Paléolithique supérieur de Kašov I en Slavaquie orientale, Slovenská archeológia, t. 40/1, s. 5-28.

Bobak D., Połtowicz-Bobak M.

2010 Osadnictwo starszej epoki kamienia na pólnocnym przedpolu Bramy Morawskiej, [w:] Transkarpackie kontakty kulturowe w epoce kamienia, brazu i wczesnej epoce żelaza, red. J. Gancarski, Krosno, s. 29-60.

Chmielewski W.

1975a Paleolit środkowy i górny, [w:] Prahistoria ziem polskich, t. 1: Paleolit i mezolit, red. W. Chmielewski, W. Hensel, Wrocław, s. 9-158.

1975b The Upper pleistocene archeological site Zwierzyniec I in Cracow, Światowit, t. 34, s. 7-59.

Complex of Upper Palaeolithic

1995 Complex of Upper Palaeolithic sites near Moravany, Western Slowakia. I, Moravany-Žakovska, excavation 1991-1992, t. 1: Moravany-Žakovska, excavation 1991-1992, red. J. Hromada, J. K. Kozłowski, Kraków.

1998 Complex of Upper Palaeolithic sites near Moravany Western Slovakia. volume II, Moravany-Lopata II (excavations 1993-1996), t. 2: Moravany-Lopata II (excavations 1993-1996), red. J. K. Kozłowski, Kraków.

Cyrek K.

1999 Menschliche Penetration der Höhlen im mittleren Teil der Krakowsko-Częstochowska-Hohebene zwischen dem 18. und 11 Jahrtausend (vom Interstadial Lascaux bis zum Interstadial Allerød, Folia Quaternaria, t. 70 , s. $269-288$. 
Cyrek K., Nadachowski A., Madeyska T., Bocheński Z., Tomek T., Wojtal P., Szyndlar Z.

2000 Excavation in the Deszczowa Cave (Kroczyckie Rocks, Czestochowa Upland, Central Poland), Folia Quaternaria, t. 71, s. 5-84.

Dagnan-Ginter A., Parczewski M.

1976 Dwie kolekcje archeologiczne z Pogórza Dynowskiego, Materiały Archeologiczne, t. 16, s. 5-28.

Gamble C. S., Davies W., Pettitt P., Richards M.

2004 Climate change and evolving human diversity in Europe during the last glacial, Philosophical Transactions of the Royal Society B, Biological Sciences, t. 359, s. 243-254.

Ginter B.

1966 Stanowisko górnopaleolityczne w Wójcicach, pow. Grodków, Materiały Archeologiczne, t. 7, s. 59-65.

Housley R. A., Gamble C. S., Street M., Pettitt P. B.

1997 Radiocarbon evidence for the Lateglacial recolonisation of Northen Europe, Proceedings of the Prehistoric Society, t. 63, s. 25-54.

Hromada J.

1998 Gravettinske sídliská v Moravanoch nad Váhom a ich miesto vo vývoji mladého paleolitu Strednej Európy, Slovenska Archeologia, t. 46/2, s. $145-167$.

Kaminská L'.

2007 The final Palaeolithic in Slavakia, [w:] Studies in the Final Palaeolithic

Settlement of the Great European Plain, red. M. Kobusiewicz, J. Kabaciński, Poznań, s. 111-127.

Kaminská L., Kozłowski J. K.

2002 Gravettian settlement on the south side of the Western Carpathians, [w:] Starsza i środkowa epoka kamienia w Karpatach polskich, red. J. Gancarski, Krosno, s. 35-58.

Kaminská L., Tomášková S.

2004 Time space systematics of Gravettian finds from Cejkov I, [w:] The Gravettian along the Danube, t. 11, red. J. Svoboda, L. Sedláčková, Brno, s. 186-216.

Klementowice

2013 Klementowice - obozowisko ze schytku epoki lodowej we wschodniej Polsce, red. T. Wiśniewski, B. Niezabitowska-Wiśniewska, Lublin.

Kozłowski J. K.

1963 Z zagadnień paleolitu Polski południowo-wschodniej, Rocznik Województwa Rzeszowskiego, t. 3, s. 5-18.

1992 Le Paléolithique des Carpates occidentaux, Préistoria Alpina, t. 28/2, s. 113-126. 
1997 Le deuxième Pléniglaciaire et l'évolution de l'art paléolithique, L'Anthropologie, t. 101, s. 24-35.

1999 Les origines de la récolonisation de la partie septentrionale de l'Europe Centrale après le pléniglaciaire, Folia Quaternaria, t. 70, s. 317-331.

2001 Dwa mikroregiony osadnictwa późnograweckiego: dolina Wisly pod Krakowem oraz dolina Wagu pod Pieštianami, [w:] Archeologia przestrzeni. Metody i wyniki badań struktur osadniczych w dorzeczach górnej Łaby i Wisty, red. J. K. Kozłowski, E. Neustupný, Kraków, s. $95-110$.

Kozłowski J. K., Kozłowski S. K.

1977 Epoka kamienia na ziemiach polskich, Warszawa.

1996 Le Paléolithique en Pologne, Grenoble.

Kozłowski J. K., Kubiak H., Welc A.

1970 A Palaeolithic site with mammoth remains at Nowa Huta, Folia Quaternaria, t. 36, s. 1-27.

Kozłowski S. K.

1977 Harpun ze stanowiska Przemyśl II, Acta Archaeologica Carpathica, t. 17 , s. 139-143.

Krawczyk M., Płonka T., Wiśniewski A.

2004 Nowe stanowisko magdaleńskie w Broniszowicach st. 2 na Górnym Śląsku, Śląskie Sprawozdania Archeologiczne, t. 46, s. 235-240.

Obłazowa Cave

2003 Obłazowa Cave. Human activity, stratigraphy and palaeoenvironment, red. P. Valde-Nowak, A. Nadachowski, T. Madeyska, Kraków.

Oliva M.

2007 Gravettien na Moravě, Praha-Brno. Retrieved from internal-pdf://OlivaGravet07-2920667397/OlivaGravet07.pdf

Otte M., Noiret P.

2004 Evolution du Gravettien au Moyen Danube, [w:] The Gravettian along the Danube, t. 11, red. J. Svoboda, L. Sedláčková, Brno, s. 8-32.

Płonka T., Wiśniewski A.

2004 New Gravettian Site in Lower Silesia (SW Poland), [w:] The Gravettian along the Danube, t. 11, red. J. Svoboda, L. Sedláčková, Brno, s. 164179.

Połtowicz M.

2004 Ślady łowców mamutów $i$ wyspecjalizowanych myśliwych na terenie Przemyśla, [w:] Dzieje Przemyśla, t. 1: Osadnictwo pradziejowe i wczesnośredniowieczne, cz. 2: Analiza źródet i synteza, red. A. Koperski, Przemyśl, s. 5-17. 
Połtowicz-Bobak M.

2013 Wschodnia prowincja magdalenienu, Rzeszów.

Sobczyk K.

1995 Osadnictwo wschodniograweckie w dolinie Wisły pod Krakowem, Kraków.

Street M., Terberger T.

1999 The last Pleniglacial and the human settlement of Central Europe: new information from the Rheinland site of Wiesbaden-Igstadt, Antiquity, t. 73 , s. 259-272.

Svoboda J. A.

2007 The Gravettian on the Middle Danube, PALEO. Revue d'archéologie préhistorique, t. 19, s. 203-220.

Svoboda J., Czudek T., Havlíček P., Ložek V., Macoun J., Přichystal A., Vlček E.

2002 Paleolit Moravy a Slezska (II.), Brno.

Svoboda J., Ložek V., Vlček E.

1996 Hunters between East and West: The Paleolithic of Moravia, New York, London.

Svoboda J., Novak M.

2004 Eastern Central Europe after the Upper Pleniglacial: changing points of observation, Archäologisches Korrespondenzblatt, t. 34, s. 463-477.

Terberger $\mathrm{T}$.

2003 Vom Gravettien zum Magdalénien in Mitteleuropa - Aspekte der menschlichen Besiedlungsgeschichte in der Zeit und des zweite Kältemaximum der letzten Eiszeit, Archäologisches Nachrichtenblatt, t. 8, S. 55-62.

2013 Le Dernier Maximum glaciaire entre le Rhin et le Danube, un réexamen critique, Mémoire de la Société préhistorique française, t. 56, s. $415-443$.

Terberger T., Street M.

2002 Hiatus or continuity? News results for the question of Pleniglacial settlement in Central Europe, Antiquity, t. 76, s. 691-698.

Valde-Nowak P.

1991 Studies in Pleistocene settlement in the Polish Carpathians, Antiquity, t. 65 , s. 593-606.

Valoch K.

1965 Jeskyně Šipka a Čertova Díra u Štramberku, Brno.

Weniger G.-C.

1987 Magdalenian settlement pattern and subsistence in Central Europe: the South-Western and Central Germany cases, [w:] The Pleistocene Old World: regional perspectives, red. O. Soffer, New York, London, s. $201-215$ 
1989 The Magdalenian in Western Central Europe: settlement pattern and regionality, Journal of World Prehistory, t. 3, s. 323-372.

Wilczyński J.

2006 The upper palaolithic workshop at the site Piekary IIa sector XXII layer 5, Sprawozdania Archeologiczne, t. 58, s. 175-203.

2007 Epigrawecka pracownia krzemienia na stanowisku Kraków ul. Spadzista $B+B 1$, Przegląd Archeologiczny, t. 55, s. 5-52.

Wilczyński J., Szczepanek A., Wojtal P., Diakowski M., Wojenka M., Sobieraj D.

2014 A Mid Upper Palaeolithic child burial from Borsuka Cave (Southern Poland), International Journal of Osteoarchaeology. Retrieved from http://onlinelibrary.wiley.com/doi/10.1002/oa.2405/abstract.

Wilczyński J., Wojtal P., Łanczont M., Mroczek P., Sobieraj D., Fedorowicz S.

2014 Loess, flints and bones: multidisciplinary research at Jaksice II Gravettian site (southern Poland), Quaternary International. Retrieved from http://www.sciencedirect.com/science/article/pii/S1040618214002109.

Wilczyński J., Wojtal P., Sobczyk K.

2012 Spatial organization of the Gravettian mammoth hunters' site at Kraków Spadzista (southern Poland), Journal of Archaeological Science, t. 39, z. 12, s. 3627-3642. Retrieved from http://www.sciencedirect. com/science/article/pii/S0305440312002129.

Wiśniewski A., Badura J., Furmanek M., Hnat M., Przybylski B., Rapiński A.

2010 Prace wykopaliskowe na stanowisku 9 w Sowinie, województwo opolskie, Badania Archeologiczne na Górnym Śląsku i ziemiach pogranicznych w latach 2007-2008, s. 15-24.

Wiśniewski A., Furmanek M., Borowski M., Kądziołka K., Rapiński A., Winnicka K.

2012 Lithic raw material and Late Palaeolithic strategies of mobility: a case study from Sowin 7, SW Poland, Anthropologie, t. 50/2, s. 391-409.

Wiśniewski A., Połtowicz-Bobak M.

2013 Paleolit, [w:] Archeologia. Górny Śląsk, red. E. Tomczak, Katowice, s. 7-31. 


\section{SETTLEMENT REGIONS ON POLISH TERRITORIES IN THE YOUNGER PHASE OF THE UPPER PALAEOLITHIC AND THE BEGINNING OF THE FINAL UPPER PALAEOLITHIC COMPARED TO THE SETTLEMENT IN CENTRAL EUROPE}

\section{Summary}

This paper concerns the comparison of the spread of the Gravettian, Epigravettian and Magdalenian settlement on Polish territories. Considering these units, Poland is a peripheral area. Both similarities and differences between these cultures are noticeable. As for the settlement occupied by both the Gravettian and Magdalenian cultures, it is visible throughout the whole southern Polish territory. Some of the exploited territories overlap closely. The differences regard more specific locations of these cultures such as the absence of the Gravettian settlement on the Kraków-Częstochowa Jurassic Upland (except the probably Early Gravettian site in the Borsucza Cave), and the lack of Magdalenian settlement in the Kraków area. Traces of Gravettian settlement were discovered in Lower Silesia, where the Magdalenian settlement is unknown, and the westernmost Magdalenian traces are located less than $50 \mathrm{~km}$ from the site at Henryków. Gravettian and Magdalenian settlement is also known from the area of the Carpathian Mountains.

The difference also consider the rate of settling Polish territories. The Pavlovian settlement includes mainly Silesia, while the younger one (Kostienki-Avdieyevo) - Lesser Poland. Moving the Gravettian settlement towards the east is associated with progressive climate changes in the course of LGM development. Meanwhile, the Magdalenian settlement occupies the whole territory of Poland in a short period of time reaching up its eastern boundaries.

The settlement structure of both cultures is different. The spread of the sites may indicate the directions of the expansion that lead along the east-west line as for the Gravettian and north-south for Magdalenian.

Adres do korespondencji:

Dariusz Bobak, Marta Poltowicz-Bobak

Instytut Archeologii, Uniwersytet Rzeszowski

ul. Moniuszki 10, 35-015 Rzeszów

adrese-mail: marta.pb@archeologia.rzeszow.pl 